\title{
Harnessing User Values to Understand Value Co-Creation and Co-Destruction in Augmented Reality Mobile Games
}

\author{
Jenny Elo \\ Faculty of IT \\ University of Jyväskylä \\ jenny.m.elo@jyu.fi
}

\author{
Juuli Lintula \\ Faculty of IT \\ University of Jyväskylä \\ juuli.lintula@jyu.fi
}

\author{
Tuure Tuunanen \\ Faculty of IT \\ University of Jyväskylä \\ tuure@tuunanen.fi
}

\begin{abstract}
This paper explores the phenomena of value cocreation and co-destruction in augmented reality $(A R)$ mobile games. More specifically, we aim to achieve an in-depth understanding of value co-creation and codestruction occurring in Pokémon GO and the user values underlying these occurrences. Service-dominant (S-D) logic provides our study with a lens for understanding users as active co-creators, codestroyers, and determinants of value. Further, the means-end theory establishes users' personal values and goals as the basis for service value determination. We uncover key values highlighted in users' positive and negative gaming experiences through a qualitative content analysis of 43 in-depth laddering interviews conducted with active Pokémon GO gamers in Finland. Our study contributes to the IS and service research literature by demonstrating how user values may be operationalized to measure and understand value cocreation and co-destruction from service users' perspective, supporting value-based design and development of digital services.
\end{abstract}

\section{Introduction}

The emergence of service-dominant (S-D) logic [13] has marked a significant change in the understanding of value creation in digital services and the role of service actors (e.g., users and providers) in the process. S-D logic asserts that the value of a product or service is always determined by the focal actor, i.e., value stems from an actor's subjective experience and interactions with other partaking actors $[3,4]$. It follows that users' value co-creation experiences reflect the success of a service $[5,6]$ and represent the basis of value creation [7]. Thus, understanding how users perceive and determine value is fundamental to design services that meet users' needs and create desired, positive experiences [8].

However, the current literature on S-D logic does not explicitly define how value is determined by users or how value co-creation and co-destruction could be measured to support service design. Moreover, literature has tended to revolve around the concept of value cocreation, overlooking the equally feasible process of value co-destruction $[9,10]$. While investigations into value co-destruction have emerged [e.g., 8], few studies have examined these two in a conjoint study. Studying value co-creation and co-destruction as two distinct yet interrelated phenomena is salient for attaining a holistic understanding of how users determine value in service use [11]. We address this research gap by exploring how value co-creation and co-destruction unfold by harnessing users' personal values. For this, we employ the means-end theory [12], which connects service value determination to the users' personal values and goals. In this view, users' personal values underlie their needs and goals for service use, thus guiding their behavior towards and evaluation of the service $[12,13]$. Therefore, investigating users' personal values underlying their service experiences enables attaining an in-depth understanding of the positive and negative value outcomes they derive from service use.

New emerging technologies, such as AR, may offer unique opportunities for value co-creation, but also value co-destruction, as they blend real and virtual world elements in service provision. Furthermore, such services that combine the physical and virtual worlds, may result in more complex positive or negative value outcomes than services that are exclusively virtual or physical [8]. To capture such potential complexities of user value determination, we opt to investigate the value co-creation and co-destruction phenomena in the context of AR mobile games. Notably, users' service experience largely determines their future behavior, word of mouth, and brand perception [14]. Thus, understanding the value derived by users ought to be of 
great interest for service design practitioners as well as researchers. Accordingly, we scrutinize the key user values underlying value co-creation and co-destruction in AR mobile games. We set the following research question: Which user values are highlighted in value cocreation and co-destruction experienced by AR mobile gamers?

We employ an earlier data set from Lintula et al. [8] study consisting of 43 in-depth laddering interviews [15]. We apply qualitative content analysis to discover the emerging key user values and connected experience descriptions. Further, we utilize the value typology of Tuunanen and Kuo [16] in identifying and depicting users' personal values as key user values underlying the experienced value outcomes. We connect the emerging key user values to both the value co-creative and codestructive experience descriptions depicted by respondents, as recent studies [e.g., 17, 18] suggest that these elements should be studied together.

We identify eight key user values in our analysis. Whereas intrapersonal and terminal value types are emphasized in users' co-creative gaming experiences, interpersonal values are emphasized in the codestructive experiences. Based on our analysis, we find that the key user values underlying value co-creation include pleasure, a sense of belonging, ambition, activity, and a healthy life, whereas, two key user values, namely social recognition and responsibility, underlie value co-destruction for users. Interestingly, the value of sociality is highlighted in both co-creative and codestructive user experiences.

\section{Theoretical background}

\subsection{Value co-creation and co-destruction within the S-D logic framework}

The S-D logic views service as a process where value is always co-created through interactive collaboration and resource integration between the participating actors [11]. Such actors comprehend service providers, who utilize their knowledge and capabilities to create superior value propositions, and users, who apply their skills and knowledge in such a co-creation process and determine the emerging value through the use of the service [19]. When co-creation of value functions properly, all participating actors become "better off" as the outcome of the process, thus, attaining positive value from the service process [20]. Vargo, Maglio, and Akaka [19] regard that such a positive value outcome resulting from value co-creation manifests as an improvement in well-being for at least one of the participating actors. Further, investigating the use of IS with the S-D logic lens, Tuunanen, Myers, and Cassab
[21] underscore the role of individual users' values and goals in the value co-creation process. This aspect is of particular interest to our study.

While S-D logic has recently acknowledged that value derived from service may be positively or negatively valenced [4], it has tended to focus on positive aspects overlooking processes with potential negative outcomes $[8,9]$. Echeverri and Skålén propose [10] value co-creation in S-D logic is an unrealistic perception, suggesting that value co-destruction may also occur and should not be overlooked by service providers. Therefore, the concept of value codestruction has emerged noting that the interactions between service providers and users do not always cocreate value but may result in unfavorable outcomes [22]. Plé and Chumpitaz Cáceres [9] defined value codestruction as accidental or intentional misuse of service systems' resources that results in a decline in the wellbeing (i.e., a negative value outcome) for at least one of the participating actors. Here, misuse refers to unexpected or inappropriate application of resources by an actor, considered as accidental or intentional, depending on the actor's motivations for such actions [22]. Value co-destruction might occur, for instance, when an online self-diagnosis service is used by a patient who lacks sufficient medical knowledge required to successfully evaluate the potential diagnoses proposed by the service. Such a service occurrence is prone to negative value outcomes in the form of a false diagnosis, leading to the patient's decreased well-being [23].

Further, research has reinforced that co-creation and co-destruction of value are tightly linked and should be studied together [e.g., 17, 18]. For example, users of the interactive outdoor game Geocaching were found to simultaneously co-create and co-destroy value as they enjoyed nature at its purest, which contradicted their very own consumption of nature whilst searching for caches [24]. Kokko, Vartiainen, and Tuunanen [18] argued that value co-creation and co-destruction interact dynamically in a service process, alternately gaining strength and dwindling. Similarly, Plé [22] has concluded that value co-destruction may appear as a value imbalance among the interacting service actors.

\subsection{Service value determination}

Traditionally, service value has been conceptualized as an outcome of a trade-off where value determination is based on the comparison of positive consequences (benefits) the user perceives in the service experience to the negative consequences (sacrifices) acquired to obtain them [25]. However, this view has been criticized as a relatively narrow approach that does not adequately reflect the dynamic value concept [26]. 
Another commonly applied definition to value has been offered by Holbrook [27:715], who describes value perceived by users as an "interactive relativistic preference experience." By this definition, value is a function of an interaction between subjects, is based on the user's personal evaluative judgment, and resides in the service experiences. Holbrook's approach to value connects well to S-D logic that captures the contextual nature of value as a foundational premise, stating, "value is always uniquely and phenomenologically determined by the beneficiary" [2:9]. Thus, the focal service actor determines the positive or negative value outcomes emerging from a service encounter. Furthermore, the value of a service may be evaluated differently by different users or by the same user in different contexts - time, place, or social and cultural environment [28].

In IS literature, the traditional way of approaching value has tended to focus on the efficiency and effectiveness of a system [21]. However, this view is somewhat limited, as it merely addresses the utilitarian (productivity-oriented) value that users can derive from the service experience. More recent literature acknowledges the significance of hedonic (pleasureoriented) value for users [e.g., 29, 30]. Tuunanen, Lintula, and Auvinen [29] found distinct differences in hedonic and utilitarian value drivers between the studied service systems. Thus, they argued services should be designed according to users' value-based drivers rather than system types. Our study adopts the means-end approach to build understanding for this very purpose. We explore users' value-based drivers and service value determination from the perspective of users' personal values. We see that this approach to value provides great means for understanding and measuring the complex and dynamic value outcomes users derive from service use.

Means-end theory [12] is based on the premise that users take part in service interactions as means to achieve desirable ends [31]. These ends represent the underlying values considered relevant by the users [15]. Consequently, the means-end theory [12] connects the users' service experiences to their personal values, what Rokeach [13:5] calls the "enduring belief that a specific mode of conduct or end-state of existence is personally or socially preferable to [its] opposite." Ordered by relative importance and influenced by culture and social environment, values represent conceptions of users' personal beliefs, refer to desirable goals that motivate action, transcend specific situations, and serve as criteria in the evaluation of actions and events [13, 32].

The means-end theory is based on George Kelly's [33] personal construct theory (PCT) in which individuals perceive and evaluate their experiences based on their personal constructs (which result from their observations and interpretations of the surrounding world). Based on PCT, all users possess individual multidimensional constructs that describe the features and behavior of objects and events, their consequences, and resulting effects on users' values. Users employ their personal constructs to determine whether service features produce desired consequences in line with their personal values $[6,16]$.

Combining the views of the means-end theory [12] with the S-D logic [1-3], we conceptualize that users participate in service interactions driven by their personal values, which create needs and goals for the service use, guiding users' determination of positive or negative value outcomes of the service. Thus, the experienced value outcomes result from users' assessment of whether the service interactions promote their personal values and goals. Positive value outcomes may emerge when users perceive that the service interactions support their personal values and goals, whereas, failure to support users' personal values or experienced value contradictions [24] in service use are more likely to result in a negative value outcome. Therefore, instead of emphasizing service attributes (features), service providers should aim to understand the users' personal values which drive the perceived value co-creation and co-destruction.

\section{Methodology}

As we aimed to investigate value co-creation and codestruction in AR mobile games, we conducted a secondary analysis of a data set of 43 in-depth laddering interviews [15] with users of a particularly well-known and representative AR mobile game, Pokémon GO. Pokémon GO may be conceptualized as a service provider offering customers value propositions via the AR game application, where gamers may integrate resources for co-creating value [8]. According to our observations of content shared by the official Pokémon GO account on YouTube, the main value propositions of Pokémon GO attempt to increase users' well-being by supporting user values of togetherness, fun, and physical exercise [34]. Earlier studies have shown Pokémon GO may increase players' physical and psychological well-being [e.g., 30, 35, 36], awareness and a sense of social unity [8]. However, also negative value outcomes have been noted, related to geographically linked biases [37] and even accidents and assaults [8], for example.

Using purposeful sampling [38], we recruited 43 respondents from local Pokémon GO Facebook groups in Finland. Respondents were aged between 19 and 62, most being employees or students, and over two-thirds female. About 80 percent of respondents reported daily gaming activity. Due to length requirements, we do not 
outline the implementation of the field study here, but detailed descriptions can be found in Lintula et al. [8]. The interviews were conducted carefully following the laddering interview technique procedure [15]. The technique is particularly suitable for modeling users' value structures according to the means-end theory models [39]. Laddering enables respondents to think critically about their service use and derived experiences, and, what is particularly relevant to our study, the relation of those experiences to their personal values and goals.

The initial study [8] elicited occurrences of value codestruction as experienced by the respondents through identifying reasoning behind the experienced negative value outcomes. However, the rich data set indicated a large number of service occurrences with positive value outcomes as well. Thus, in this study, we conducted a secondary analysis of the data to attain insights on both value co-creation and value co-destruction perceived by gamers, focusing on their underlying personal values. We analyzed the data through qualitative content analysis, which supports the systematic examination and reduction of qualitative data to discover and understand recurring meanings therein [40]. The method was deemed particularly suitable for addressing our research objective, as it enabled the systematic identification and classification of the key user values and exploring their connection to value co-creation and co-destruction occurrences experienced by gamers.

First, the first author validated and recoded the initial negative value codes in the data set. These represented the value co-destructive user experiences. Subsequently, the author systematically examined all the 43 transcribed interviews word-by-word to determine the positively valenced [4] experiences from the data. The positive experience descriptions were inductively labelled with descriptive value codes. The division of positively and negatively valenced experiences was maintained throughout the analysis to allow later comparison of the distinct user values underlying the co-creative and co-destructive experience descriptions.

Second, we employed the value typology framework (cf. Table 1) by Tuunanen and Kuo [16] as the theoretical basis for classifying the determined value codes and applied a connected classification dictionary to define the rules and specifications for our analysis. The value typology is based on Rokeach's [13] seminal value framework, and divides values into four highlevel value types. First, values are either interpersonal (concerned with other people and social contexts, i.e., other-centered) or intrapersonal (personally experienced and relevant to each user, i.e., self-centered). Second, values can be distinguished into terminal and instrumental types. A terminal value represents a goal (end-state of existence) that a user aims to achieve; an instrumental value represents a behavior (a "mode of conduct") used to achieve an individual terminal value. Combinations of these value types form a matrix of four value categories - social, moral, personal, and competency - which contain 36 individual value constructs based on Rokeach's [13] original value list.

Tuunanen and Kuo [16] utilize the typology to distinguish value differences between mobile service users in different cultures. Discussing the typology against other existing ones (e.g., Schwartz [32]) we deemed the framework with its multi-level, yet, easy to grasp value classification, and the extensive list of value constructs, an effective foundation for performing systematic and reliable classification of the value codes in our study.

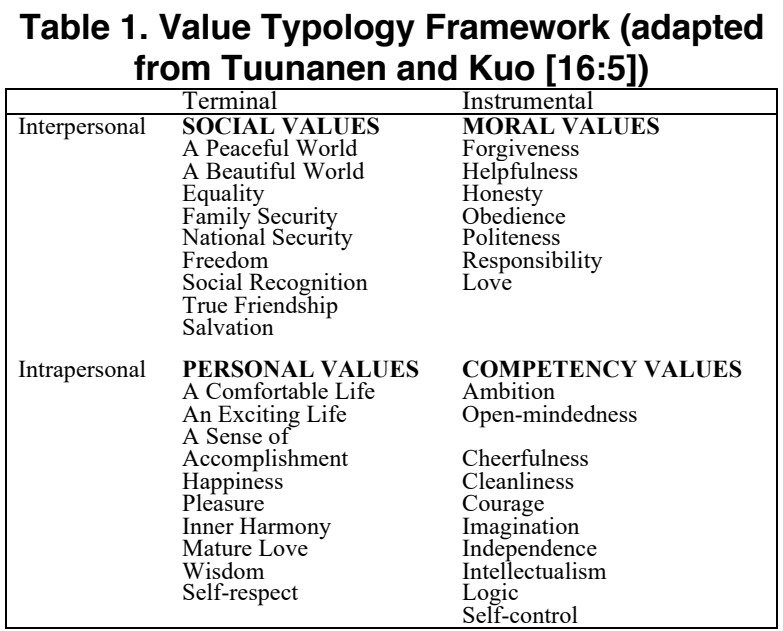

Each of the value codes and connected experience descriptions established in the first analysis phase were classified under one value construct, and consequently allocated to the associated value categories and highlevel value types by the first author, as illustrated in the following example: "It truly provides me with so many fun moments, some extra enjoyment to life" (experience description) $\rightarrow$ fun/enjoyment (value code) $\rightarrow$ pleasure (value construct) $\rightarrow$ personal (value category) $\rightarrow$ intrapersonal (value type) $\rightarrow$ terminal (value type) $\rightarrow$ co-creative (experience category). The interpretations of each classification were discussed and evaluated with the other authors. During the analysis, we extended the typology ad-hoc with five new value constructs Activity, A Healthy Life, A Sense of Belonging, Justice, and Sociality to adequately cover the user values emerging from our data. Furthermore, we merged the original constructs of Family Security and National Security into Security to better represent the variety of respondents' security-related experiences. 
Third, we quantified all confirmed value constructs, categories, and types to discover the frequency of their occurrence in the data. This enabled us to perform statistical comparisons between users' value co-creative and co-destructive experiences and to determine the key user values underlying these. Following the study of Tuunanen and Kuo [16], the value categories and types were subjected to two-sided t-tests assuming unequal variances between and within the value co-creative and co-destructive experience categories. We determined thirteen value constructs connected to the value cocreative experiences and twenty-six to the codestructive ones. In order to present the most focal user values, we tested different significance thresholds to derive comprehensive yet concise findings. Based on our assessment, we determined a nine percent threshold in proposing key user values underlying gamers' experienced value co-creation and co-destruction occurrences.

\section{Findings}

Table 2 describes the overall distribution of user value types and categories in the data, depicting the number of times each value type and category occurred in conjunction with respondents' value co-creative and co-destructive experience descriptions. The percentages represent the totality of each value type and category, providing an overview of their relative importance in both co-creative and co-destructive experiences. Table 2 also depicts the t-values and statistical significance for the observed differences.

Table 2. Distribution of user value types and categories

\begin{tabular}{|c|c|c|c|c|c|}
\hline \multirow{2}{*}{$\begin{array}{l}\text { Value type / } \\
\text { category }\end{array}$} & \multicolumn{2}{|c|}{$\begin{array}{l}\text { Value co-creative } \\
\text { experiences }(n=152)\end{array}$} & \multicolumn{2}{|c|}{$\begin{array}{l}\text { Value co-destructive } \\
\text { experiences }(n=317)\end{array}$} & \multirow[t]{2}{*}{ t-value } \\
\hline & $\mathrm{n}$ & $\%$ & $\mathrm{n}$ & $\%$ & \\
\hline Interpersonal & 42 & 27.00 & 204 & 64.00 & $8.693 * * *$ \\
\hline Intrapersonal & 110 & 72.00 & 113 & 36.00 & 0.178 \\
\hline t-value & & $5.648 * * *$ & & $4.129^{* * *}$ & \\
\hline Terminal & 93 & 61.00 & 155 & 49.00 & $3.176^{* *}$ \\
\hline Instrumental & 59 & 39.00 & 162 & 51.00 & $6.836^{* * *}$ \\
\hline t-value & & $2.533^{*}$ & & 0.338 & \\
\hline Social & 20 & 13.00 & 96 & 30.00 & $5.592 * * *$ \\
\hline Moral & 22 & 15.00 & 108 & 34.00 & $7.412 * * *$ \\
\hline Personal & 73 & 48.00 & 59 & 19.00 & 0.975 \\
\hline Competency & 37 & 24.00 & 54 & 17.00 & 1.757 \\
\hline
\end{tabular}

We found that in Pokémon GO, intrapersonal values were significantly more emphasized $(p<0.001 ; 72 \%)$ in respondents' co-creative experience descriptions than interpersonal values $(27 \%)$, and interpersonal values were significantly more emphasized $(p<0.001 ; 64 \%)$ in the value co-destructive experiences than intrapersonal values $(36 \%)$. Terminal values were significantly more emphasized $(\mathrm{p}<0.05 ; 61 \%)$ in the value co-creative experience descriptions than instrumental values (39\%), but no significant difference was found between the terminal $(49 \%)$ and instrumental (51\%) value types in the co-destructive experiences. However, terminal values were significantly $(p<0.01)$ more emphasized in the value co-creative than co-destructive experience descriptions, and instrumental values significantly $(p<0.001)$ more emphasized in the value co-destructive than co-creative experience descriptions.

We performed t-tests between the two experience categories in the four value categories, and found a statistically significant $(p<0.001)$ difference between the co-creative and co-destructive gaming experiences in the social and moral value categories. The value codestructive experiences were emphasized in both value categories. Further, no statistical significance was discovered between the personal and competency value categories. However, in this study, the latter two value categories had a more prominent role in respondents' co-creative gaming experiences, especially in the personal values category $(48 \%$ of the co-creative experiences, only $19 \%$ of the co-destructive gaming experiences).

At the value construct level, we determined eight key user values for Pokémon GO based on the set $9 \%$ significance threshold. Five of the values (pleasure, $a$ sense of belonging, ambition, activity, and a healthy life) were highlighted in the gamers' co-creative experiences, two (social recognition and responsibility) in the co-destructive, and one (sociality) was almost equally represented in both experience categories. The key user values and their significance percentages in respondents' co-creative and co-destructive gaming experiences are depicted in Figure 1. Next, we present the user values in more detail from positive to negative emphasis.

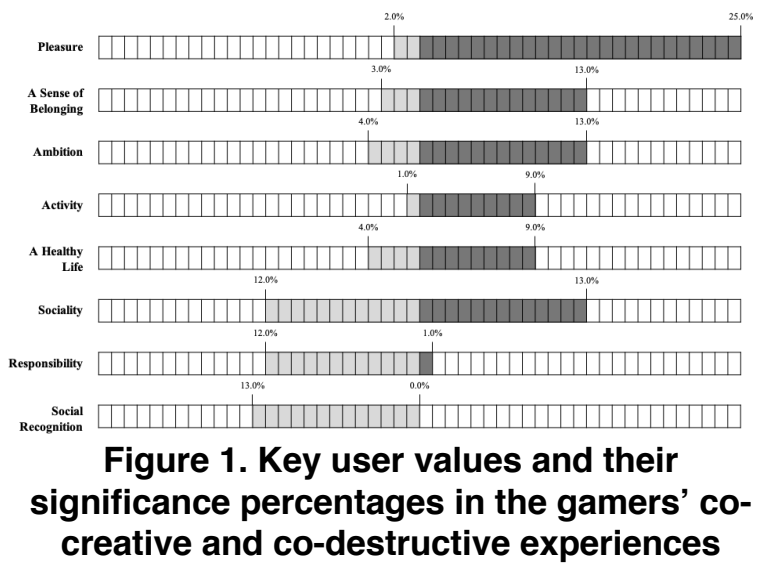

Pleasure (pos. 25\%, neg. 2\%) emerged as the most significant user value underlying value co-creation. The value construct represents intrapersonal and terminal 
value types and thus belongs to the personal values category. The construct embraces feelings such as enjoyment, relaxation, and fun. It also includes gamers' experiences of the game as a pastime. Based on our findings, playing Pokémon GO is a central part of everyday life for many:

...during the day, even at home, I go from zero to six times inside the game...I just browse for what is there...I play it for my own fun and enjoyment, like just for the sake of killing time. (Respondent 34)

We found that gamers often use Pokémon GO as entertainment during traveling from one place to another, such as home to office. Furthermore, the gamers' experiences of relaxation (also classified under the pleasure value construct) were associated with gaming balancing out the demands of work:

...I have a stressful job that requires concentration and thinking and takes a lot of time and energy so I think it is so great that after a challenging and hard day of work when you close those office doors you can simply play Pokémon GO and become fully absorbed in that world... (Respondent 16)

The overall significance of the pleasure value in the value co-destructive gaming experiences was only two percent. The few occurrences where pleasure value was connected with negative gaming experiences were related to the game hindering perceived fun or enjoyment (e.g., in-game technical issues, misbehaving fellow-gamers, fading initial interest, and the perceived simplicity of the game).

A sense of belonging (pos. 13\%, neg. 3\%) is the first new value construct we proposed to the typology. We classified the construct as an interpersonal and terminal value, i.e., a social value. Here, the social aspect of the game and a resulting sense of togetherness or community appeared to underlie value co-creation with Pokémon GO for gamers. A few experiences of nostalgia were also regarded as the sense of belonging value. These were related to childhood memories like playing with the Game Boy console or Pokémon cards. Further, our findings showcase how families used the game together, thus co-creating value by increasing a sense of belonging:

...I get to have more contact with the kid, or with my son...now that we are on these trips...for many hours... we end up talking about everything. I think we are much better off now and more open... (Respondent 11)

The few co-destructive gaming experiences related to the value of sense of belonging included the perceptions of lack of gaming community and being excluded from the game based on geographic location.
Ambition (pos. 13\%, neg. 4\%) represents an intrapersonal instrumental value, belonging to the competency values category. Here, we found that the user values of goal orientation (e.g., a desire to collect all the Pokémon) and competition with others and/or oneself appeared to underlie value co-creation:

...my goal is to collect everything that you can get in Finland and all the different Pokémon...well mostly I'm competing against myself...I think it's a good thing that there is always something to achieve in the game. (Respondent 33)

The ambition value construct was underlying value co-destruction in service instances where gamers were unable to achieve personal goals in competition, physical resources were breaking down, other gamers were violating the rules, and the game was malfunctioning.

As the second addition to the value typology, we proposed the construct activity (pos. $9 \%$, neg. $1 \%$ ) in the competency values category, representing intrapersonal and instrumental value types. Activity heralded value co-creation as gamers perceived an increase in physical activity supported by Pokémon GO. In some cases, an increase in time spent outdoors was also connected to positive gaming experiences:

And for me the aspect of exercise is important here and then getting out with the device...it involves this outdoor activity and having to get away, getting away from that computer... (Respondent 24)

The construct of activity appeared to also underlie value co-destruction in some instances. For example, ingame technical issues discouraged gamers or hindered their goal of physical activity, and gamers perceived boredom (inactivity) when playing alone.

As the third new value construct, we proposed a healthy life (pos. 9\%, neg. 4\%). It represents an intrapersonal and terminal value type, a personal value. Here, our findings mainly included value co-creative experiences where Pokémon GO supported gamers' physical health, but the construct also heralded improved well-being in the form of coping with everyday life or improved quality of sleep:

...in my opinion, this has been good for health so walking in great amounts, twenty-thirty kilometers a day... after all it is, it keeps people in good shape...we have spent time outdoors but never walked like this and yes I do think it is only a good thing...for most people's health, it does good to be outdoors. (Respondent 10)

The few co-destructive gaming experiences connected to the value construct of healthy life concerned the gamers' perceived challenges of 
maintaining health and well-being, and gaming causing harm to health due to, e.g., lack of sleep and gamerelated physical concerns.

Sociality (pos. $13 \%$, neg. $12 \%$ ) was the only value construct highlighted as underlying both co-creative and co-destructive gaming experiences. It is also proposed as the fourth new value construct, classified as interpersonal and instrumental. Here, the positive user values of spending time with family and friends while gaming and sharing of experiences were underlying value co-creation:

...we have a really close and great group that we play with...you can like talk and socialize... if it weren't for that I probably would have quit playing a long time ago or at least drastically reduced it... (Respondent 4)

...of course, it's always nice to compare with a friend, for example, what stage you are at... (Respondent 39)

The sociality value construct also featured codestructive gaming experiences relating to neglect of social relationships or time with family when users prioritized the game over other priorities, hobbies, or essential relationships. Some respondents found it difficult to choose between gaming and maintaining social relationships outside the game. Some mentioned that they felt negative about gaming around their friends or spouse but still could not resist the temptation. Thus, value co-destruction occurred as the game seemed to be taking away gamers' capacity to be "present" in the moment:

...it also a little negatively affects...the interaction between me and my spouse when the other is too focused on the game...maybe you miss on some things that you would share otherwise... (Respondent 41)

Experienced lack of sociality within the game stem from in-game technical issues, experiences of being left out from a group of friends, and other unmet expectations regarding sociality:

I have probably not talked to any new people, just a couple of times, talking and taking down a Gym if it has happened to be there. That kind of community is missing from the game... (Respondent 12)

Responsibility (pos 1\%, neg 12\%) emerged as one of the two negatively emphasized value constructs underlying value co-destruction. Responsibility represents an interpersonal and instrumental, moral value. The construct addressed reliability, perceived disappointment, and "wasted" in-game efforts. Here, most of the respondents' experiences were related to gaming activities contradicting the user value of responsibility (e.g., choosing to play over other priorities, being late or neglecting work, playing while driving):

I have sometimes accidentally gone astray on my way to work when I've gone after a rare Pokémon, yeah, I have been late from work because of it...It is such an important thing, however, to be on time... (Respondent 11)

Social recognition (pos. $0 \%$, neg. 13\%) was the most emphasized value construct underlying the respondents' value co-destructive gaming experiences. The construct did not occur in connection with respondents' cocreative experiences. As the name of the construct suggests, it belongs to the social values category representing interpersonal and terminal value types. The construct comprised respondents experienced lack of acceptance and appreciation from others and their personal image suffering from playing the game. Such experiences were mostly related to negative gaming experiences with non-users (e.g., family, relatives, friends, or strangers) unfavorable attitudes towards Pokémon GO, or the overall lack of gaming knowledge:

...at some point everyone was playing it, and at some point, it changed...cool became a little bit maybe a nerdy thing...maybe they are more like wondering that someone is still playing this... (Respondent 13)

\section{Discussion}

Our study has developed an in-depth understanding of emerging key user values in AR mobile games and connected these with users' value co-creative and codestructive service use experiences. Thus, we have pinpointed user values that underlie value co-creation (where a service interaction results in an increase in a focal actor's well-being, i.e., a positive value outcome) and value co-destruction (where a service interaction results in a decline in the focal actor's well-being, i.e., a negative value outcome). As the main finding, we propose eight user values underlying the emergence of positively or negatively valenced value outcomes in the use of Pokémon GO. More specifically, our analysis found five key user values underlying value co-creative experiences (i.e., service interactions with positive value outcomes) and two key user values underlying value co-destructive experiences (i.e., service interactions with negative value outcomes). Furthermore, one key user value was equally emphasized in both experience categories. The emerging key user values manifest as users' value-based drivers for value co-creation or co-destruction.

In line with the value propositions of Pokémon GO [34], our findings showcase that the game supports the personal values of pleasure and a healthy life, the competency values of ambition and activity, the moral 
value of sociality, and the social value of a sense of belonging. The most emphasized value types underlying the gamers' co-creative experiences were, thus, intrapersonal and terminal. These findings suggest that the users have successfully integrated the resources for co-creation of value proposed by the service. While our findings support previous studies emphasizing the central role of fun and enjoyment [e.g., 30], physical activity and well-being [e.g., 30, 35, 36], and sociability [e.g., 8, 30, 35] in Pokémon GO, we also introduce underexamined positive value-based drivers for gaming such as ambition.

On a negative note, our findings underscore that interpersonal values were particularly underlying users' co-destructive experiences. Interestingly, the moral values of responsibility and sociality and the social value of social recognition emerged in conjunction with users' value co-destructive experiences, which contrasts the value propositions offered by Pokémon GO [34] and extends the findings of previous studies. This indicates that value co-creation or co-destruction may be difficult to manage through general co-creation practices such as adjusting value propositions and integrating resources for co-creation. As highlighted in previous literature [e.g., 41, 42], our findings reinforce the understanding that the service provider and users' interactions do not take place in isolation but as a part of a wider network of actors. For example, the users' interactions with other users and non-users greatly influence the service experience. Thus, we regard that practitioners ought to pay close attention to the totality of value creation (i.e., both co-creation and co-destruction, and diversity of actors) and actual value outcomes as derived by users. Our study presents a suitable means for inquiring such insights.

While our empirical findings are derived from a particular AR mobile game, namely Pokémon GO, the study has broader implications for research and practice. First, our study demonstrates how user values may serve as one potential foundation for understanding service value determination, and how they may be harnessed to support value-based design and development of digital services. Our findings support the notion that the value perception based on user values may provide a solid basis for a user-centric, in-depth understanding of value co-creation and co-destruction in digital services. Based on user values, we defined the value structure for Pokémon GO (Figure 1). The value structure, depicted as a value meter map, presents the key user values for the service and displays their significance among the users' gaming experiences. Such a value meter map enables identifying and communicating the key valuebased drivers for service use and reveals the negatively perceived user values. Connecting the relevant service attributes (features) and consequences to particular values relevant for users helps pinpoint service features that facilitate value co-creation for users. Perhaps more importantly, the exploration showcases the experiences and associated service features that underlie value codestruction as perceived by users. Such a holistic exploration of user values underlying service value determination may be utilized for facilitating, directing and prioritizing service design and development efforts, preventing negative value outcomes and fostering value co-creation. Thus, the approach introduced in our study may be used to design services (service features, in particular) that support positive value outcomes and motivate users to engage in value co-creation while minimizing the negative value outcomes that drive them away from the service.

Second, our investigation into users' value-based drivers for co-creation and co-destruction supports the suggestions that users' experiences and value determination from a service may result in either positive or negative value outcomes [4, 18]. Our findings show that a joint consideration of value cocreation and co-destruction provides a dynamic and comprehensive view of how the service presents itself for the users. Thus, we argue that an aggregated analysis of both positive and negative value determination is needed to establish a holistic understanding of users' service experiences.

Third, as the value typology of Tuunanen and Kuo [16] enabled us to effectively and systematically classify user values, we suggest the typology may provide a useful foundation for studying and analyzing user values underlying other digital services as well. Moreover, we find that laddering interviews [15] are particularly well suited for the value-based analysis and classification of values through the typology. Tuunanen and Kuo [16] examined the user values at the value category level and cautioned that though the four categories are simple to apply, they reduce the ability to perform detailed comparisons of the differences among users concerning the specific value constructs. Thus, we classified the values up to the value construct level, showcasing how individual value constructs may provide access to more detailed information about the values relevant to the users' experiences. Useful information was found from the users' value structures already when considering the value types and categories. Thus, we find the typology may serve researchers and practitioners in various ways as it allows adjusting the level of analysis to distinct needs of research and service design.

Finally, our findings support zooming in on the user level in conceptualizing value creation, especially for service design purposes. The user perspective has been suggested, for example, by Grönroos and Voima and [42] Tuunanen et al. [29]. In contrast, Lintula et al. [8] 
have acknowledged that a holistic ecosystem perspective, featured in the recent views of servicedominant (S-D) logic [3, 4], may be useful in accounting for effects of value creation between multiple actors and complex service systems. Our findings support the view that, especially when considering digital service design, it is essential to understand how the service value is created or emerges for its users.

\section{Conclusions}

In this study, we explored users' experiences of value co-creation and co-destruction in the AR mobile games context. We identified eight key user values, namely pleasure, a sense of belonging, ambition, activity, a healthy life, social recognition, responsibility and sociality. Employing the S-D logic [1-3] lens in understanding users as active co-creators, co-destroyers, and determinants of value, we established the emerging key user values as the basis for service value determination [12]. Thus, we contribute to the IS and service research literature by demonstrating how user values may be harnessed in understanding service value determination and how they may be operationalized to support the value-based design and development of digital services.

Further, our findings add to the user-centric understanding of value co-creation and co-destruction phenomena in digital services, and more specifically, in AR mobile games. Focusing on user values and applying the value typology framework of Tuunanen and Kuo [16] enabled us to view the drivers underlying the emergence of positively and negatively valenced value outcomes of service interactions, bringing new insights to the S-D logic discourse on value co-creation and co-destruction. Our findings reinforce the applicability of the value typology of Tuunanen and Kuo [16] and the laddering interview technique [15] to classify user values and understand their different dimensions to support value-based service design. We also proposed new value constructs to expand the typology.

As a practical contribution, we shed light into the values that drive the use of AR mobile games (value cocreation) as well as the user values highlighted by the users' negative experiences (value co-destruction). The proposed key user values should be considered by AR mobile game design and development practitioners in their endeavor to enhance service interactions with gamers.

As a limitation, the data set employed in our analysis was collected from the perspective of the users' value co-destructive gaming experiences. However, the richness of the data also allowed for a fruitful exploration of gamers' value co-creative experiences.
Further, our analysis is based on only one AR mobile game, Pokémon GO, and the interviews were conducted in only two geographical locations in Finland. Thus, even within the context of the investigated AR mobile game, the results may not indicate how the user values are distributed in different countries or user groups. We encourage future studies to explore user values underlying value co-creation and co-destruction experiences in different digital service contexts to better understand the service user perspective and value determination.

\section{References}

[1] S.L. Vargo and R.F. Lusch, "Evolving to a New Dominant Logic for Marketing", Journal of Marketing, 68(1), 2004, pp. 1-17.

[2] S.L. Vargo and R.F. Lusch, "Service-dominant Logic: Continuing the Evolution", J. of the Acad. Mark. Sci, 36(1), 2008, pp. 1-10.

[3] S.L. Vargo and R.F. Lusch, "Institutions and Axioms: an extension and update of service-dominant logic", J. of the Acad. Mark. Sci, 44(1), 2016, pp. 5-23.

[4] S.L. Vargo, K. Koskela-Huotari, and J. Vink, "ServiceDominant Logic: Foundations and Applications", In the Routledge Handbook of Service Research Insights and Ideas. Routledge, 2020, pp. 3-23.

[5] B.J. Babin and K.W. James, "A brief Retrospective and Introspective of Value", European Business Review, 22(5), 2010, pp. 471-478.

[6] T. Tuunanen and K. Peffers, "Population Targeted requirements Acquisition", European Journal of Information Systems, 27(6), 2018, pp. 686-711.

[7] Prahalad, C.K. and V. Ramaswamy, The Future of Competition: Co-Creating Unique Value with Customers, Harvard Business School Press, Boston, 2004.

[8] J. Lintula, T. Tuunanen, M. Salo, and M.D. Myers, "When Value Co-Creation Turns to Co-Destruction: Users' Experiences of Augmented Reality Mobile Games", In Proceedings of the 39th International Conference on Information Systems, ICIS, 2018, 1-17.

[9] L. Plé and R. Chumpitaz Cáceres, "Not Always Cocreation: Introducing Interactional Co-destruction of Value in Service-dominant Logic", Journal of Services Marketing, 24(6), 2010, pp. 430-437.

[10] P. Echeverri and P. Skålén, "Co-creation and Codestruction: A Practice Theory-based Study of Interactive Value Formation", Marketing Theory, 11(3), 2011, pp. 351-373.

[11] J. Lintula, T. Tuunanen, and M. Salo, "Conceptualizing the Value Co-Destruction Process for Service Systems: Literature Review and Synthesis", In Proceedings of the 50th Hawaii International Conference on System Sciences, HICSS, 2017, 1632-1641.

[12] J. Gutman, "A Means-End Chain Model Based on Consumer Categorization Processes", Journal of Marketing, 46(2), 1982, pp. 60-72.

[13] Rokeach, M., The Nature of Human Values, Free Press, New York, 1973. 
[14] M. Åkesson, B. Edvardsson, and B. Tronvoll, "Customer Experience from a Self-service System Perspective", Journal of Service Management, 25(5), 2014, pp. 677-698.

[15] T.J. Reynolds and J. Gutman, "Laddering Theory Method, Analysis, and Interpretation", Journal of Advertising Research, 28(1), 1988, pp. 11-31.

[16] T. Tuunanen and I.Te Kuo, "The Effect of Culture on Requirements: A Value-based View of Prioritization", European Journal of Information Systems, 24(3), 2015, pp. 295-313.

[17] T. Tuunanen, E. Kazan, M. Salo, R. Leskelä, and S. Gupta, "From Digitalization to Cybernization: Delivering Value with Cybernized Services", Scandinavian Journal of Information Systems, 13(2), 2019, pp. 83-96.

[18] J. Kokko, T. Vartiainen, and T. Tuunanen, "Value CoCreation and Co-Destruction in Online Video Games: An Exploratory Study and Implications for Future Research", In Proceedings of the 51st Hawaii International Conference on System Sciences, HICSS, 2018.

[19] S.L. Vargo, P.P. Maglio, and M.A. Akaka, "On Value and Value Co-creation: A Service Systems and Service Logic Perspective", European Management Journal, 26(3), 2008, pp. 145-152.

[20] C. Grönroos, "Service Logic Revisited: Who creates Value? And Who Co-creates?", European Business Review, 20(4), 2008, pp. 298-314.

[21] T. Tuunanen, M.D. Myers, and H. Cassab, "A Conceptual Framework for Consumer Information Systems Development", Pacific Asia Journal of the Association for Information Systems, 2010, 47-66.

[22] L. Plé, "Why Do We Need Research on Value Codestruction?", Journal of Creating Value, 3(2), 2017, pp. 162-169.

[23] N. Robertson, M. Polonsky, and L. McQuilken, "Are my symptoms serious Dr Google? A resource-based typology of value co-destruction in online self-diagnosis", Australasian Marketing Journal (AMJ), 22(3), 2014, pp. 246-256.

[24] T. Vartiainen and T. Tuunanen, "Value Co-Creation and Co-Destruction in an IS Artifact: Contradictions of Geocaching", In Proceedings of the 49th Hawaii International Conference on System Sciences, HICSS, 2016, 1266-1275.

[25] V.A. Zeithaml, "Consumer Perceptions of Price, Quality, and Value: A Means-End Model and Synthesis of Evidence", Journal of Marketing, 52(3), 1988, pp. 2-22.

[26] R. Sánchez-Fernández and M.Á Iniesta-Bonillo, "The Concept of Perceived Value: a Systematic Review of the Research", Marketing Theory, 7(4), 2007, pp. 427-451.

[27] M.B. Holbrook, "Consumption Experience, Customer Value, and Subjective Personal Introspection: An Illustrative Photographic Essay", Journal of Business Research, 59(6), 2006, pp. 714-725.

[28] M.A. Akaka, S.L. Vargo, and R.F. Lusch, "An Exploration of Networks in Value Cocreation: A ServiceEcosystems View", In S.L. Vargo and Robert F. Lusch (eds.), Special Issue - Toward a Better Understanding of the Role of Value in Markets and Marketing, Emerald Group Publishing Limited, Bingley, 2012, 13-50.

[29] T. Tuunanen, J. Lintula, and A. Auvinen, "Unboxing Cocreation of Value: Users' Hedonic and Utilitarian
Drivers", In Proceedings of the 52nd Hawaii International Conference on System Sciences, HICSS, 2019, 14061415.

[30] T. Kari, J. Arjoranta, and M. Salo, "Behavior change types with Pokémon GO", In Proceedings of the 12th International Conference on the Foundations of digital Games, 2017, 1-10.

[31] A.S. Khalifa, "Customer Value: a Review of Recent Literature and an Integrative Configuration", Management Decision, 42(5), 2004, pp. 645-666.

[32] S.H. Schwartz, "'An Overview of the Schwartz Theory of Basic Values", Online Readings in Psychology and Culture, 2(1), 2016, Retrieved Jan 10, 2020 https://doi.org/10.9707/2307-0919.1116.

[33] Kelly, G.A., The Psychology of Personal Constructs, Vol. 1. A Theory of Personality. Vol. 2. Clinical Diagnosis and Psychotherapy, W. W. Norton, New York, 1955.

[34] The Official Pokémon YouTube channel, "'Discover Pokémon in the Real World with Pokémon GO!", 2015, $\begin{array}{llll}\text { Retrieved Jun 26, } & 2020\end{array}$ https://www.youtube.com/watch?v=2sj2iQyBTQs

[35] J. Paavilainen, H. Korhonen, K. Alha, J. Stenros, E. Koskinen, and F. Mäyrä, "The Pokémon GO Experience: A Location-Based Augmented Reality Mobile Game Goes Mainstream", In Proceedings of the 2017 CHI Conference on Human factors in Computing Systems, 2017, 24932498.

[36] T. Althoff, R.W. White, and E. Horvitz, "Influence of Pokémon Go on Physical Activity: Study and Implications", Journal of Medical Internet Research, 18(12), 2016, pp. 315.

[37] A. Colley, et al., "The Geography of Pokémon GO: Beneficial and Problematic Effects on Places and Movement", In Proceedings of the 2017 CHI Conference on Human factors in Computing Systems, 2017, 11791192.

[38] Patton, M.Q., Qualitative research \& evaluation methods: integrating theory and practice, SAGE Publications, Thousand Oaks, 2015.

[39] T. Modesto Veludo-de-Oliveira, A. Akemi Ikeda, and M. Cortez Campomar, "Laddering in the Practice of Marketing Research: Barriers and Solutions", Qualitative Market Research, 9(3), 2006, pp. 297-306.

[40] Roller, M. and P. Lavrakas, Applied Qualitative Research design: A Total Quality Framework Approach, Guilford Press, New York, 2015.

[41] S.L. Vargo and R.F. Lusch, "Service-dominant logic 2025", International Journal of Research in Marketing, 34(1), 2017, pp. 46-67.

[42] C. Grönroos and P. Voima, "Critical Service Logic: Making Sense of Value Creation and Co-creation", J. of the Acad. Mark. Sci, 41(2), 2013, pp. 133-150. 